\title{
Penile prostheses for the management of the neuropathic bladder and sexual dysfunction in spinal cord injury patients: long term follow up
}

\author{
Y Kimoto MD, E Iwatsubo MD \\ Section of Urology, Labor Welfare Corporation, Spinal Injuries Center, Iizuka, 820, \\ Japan.
}

During the last 10 years, 90 penile prostheses were implanted in 82 patients with spinal cord injury. Surgery was done 1 month to 25 years (average 4.8 years) after the injury. The follow up period ranged from 1 to 10 years (average 4 years). A prosthesis was implanted for urinary management in 51 patients $(62 \%)$, for sexual dysfunction in 10 patients $(12 \%)$ and for both purposes in 21 patients $(26 \%)$. Ninety-three per cent of the patients who used the implant for urinary management and $64 \%$ of the patients who used it for sexual dysfunction were satisfactory. We experienced three extrusions and nine surgical removals due to pain, difficulty of catheterisation and infection (the complication rate was $13.3 \%$ ). Generally speaking, a penile prosthesis improves the quality of life of patients with spinal cord injury significantly; however, extrusion and infection are still significant problems.

Keywords: penile prosthesis; spinal cord injury; urinary appliance; urinary infections; sexual dysfunction; neuropathic bladder.

\section{Introduction}

In our earlier report, ${ }^{1}$ we showed that a penile prosthesis is an effective manoeuver for the treatment of urinary incontinence and sexual dysfunction of patients with spinal cord injury. However, the complication rate of penile prosthesis surgery in spinal cord injury is significantly high $(8-25 \%)^{2-5}$ in comparison with other impotent patients $(2.2 \%){ }^{5}$ We reviewed the results of the last 10 years in order to define the cause of failure and to contribute towards the improvement of the high complication rate.

\section{Materials and methods}

During the last 10 years, 82 patients (29 quadriplegics, 32 paraplegics and 21 walking patients, one with caudal injury) received a penile prosthesis. They were injured at ages between 14 and 67 years (average 4.8 years). Fifty-one patients received the implant for urinary management, 10 for sexual

Correspondence to Dr Iwatsubo. dysfunction and 21 for both purposes. The types of implanted prostheses were 55 (61\%) Shirai (Koken Co Ltd, Tokyo) type (silicone, semi-rigid), ${ }^{1,6} 25$ (27\%) SIC (Spinal Injuries Center) type (Fig 1), 6 (7\%) AMS Hydroflex (American Medical Systems, Minnetonka, Minnesota). The SIC type implant of our product is made of silicone and is malleable at the mid portion for concealment. The diameter is $10 \mathrm{~mm}$. All patients were informed before surgery

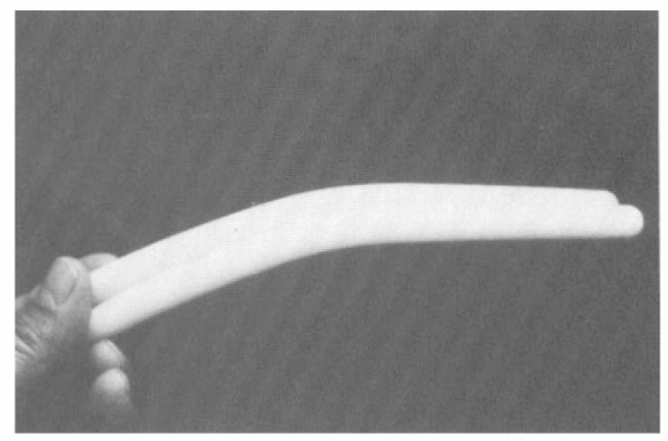

Figure 1 Spinal Injuries Center (SIC) type malleable prosthesis (all silicone material). 
of the quality of each prosthesis, the risk of possible prosthesis infection and its limitation of function compared to physiological erection. Prostheses exchange operations had to be done in eight patients because of the recipients' dissatisfaction with the cosmetic and functional aspects of implanted prosthesis. Eight Shirai type implants were exchanged for longer ones, one AMS 600 and six SIC types, to improve their quality. An infrapubic vertical approach was used in every case. Also, preoperative and postoperative antibiotics (cephalosporin i.v. followed by aminoglycocide i.m.) were used for 5-17 days (average 9 days) in every case. The indwelling catheter was removed on the 7 th postoperative day. All the patients were interviewed at their last visit to our clinic. The questionnaire dealt with the loss of the condom catheter, the improvement of self catheterisation and sexual life.

\section{Results}

Ninety patients had received a penile prosthesis initially (eight patients had received implants twice). There were three extrusions and six surgical removals because of infection. Four losses out of these nine losses occurred 1 year or more after the implantation. In two patients with AMS 600 , the prosthesis was removed because of urethral stricture, causing difficulty with catheterisation. In one patient with an L1 incomplete lesion, the prosthesis was removed because of aggravation of causalgia. Table I reviews the complications. The overall complication rate was $13.3 \%(12 / 90)$ with an infection rate of $10 \%(9 / 90)$. Responses were obtained from all patients interviewed about their satisfaction during their last visit to our clinic. The results show that 64 out of $69(93 \%)$ patients who underwent implantation surgery for urinary management expressed satisfaction. The SIC type was most appreciated since improvement has made it firm enough to maintain satisfactory intercourse and flexible at the base of the penis, fitted for self catheterisation or holding a urinary appliance. Sixteen out of the $25(64 \%)$ patients who used the implant for sexual dysfunction expressed satisfaction, although no improvement of sexual sensation, ejaculatory function or infertility were noted. Information about sexual satisfaction from the female partners was not obtained.

\section{Discussion}

As Smith and his colleagues mention, ${ }^{7}$ a penile prosthesis allows the patient to use a condom catheter more effectively and self catheterisation is more easily performed by lengthening and straightening the penis. The high satisfaction rate for urinary management of our study proved that this is true. For patients with a condom catheter, the frequency of it slipping off during transfer from bed to wheelchair and vice versa is reduced and the frequency of penile skin laceration is also reduced. For patients using self catheterisation, a penile prosthesis makes catheterisation easier since the penis can be fixed upright without holding it. Thus even quadriplegic patients could self catheterise themselves. As for the treatment of erectile impotence, a vacuum constricting device $(\mathrm{VCD})^{8}$ and intracavernous self injection' of papaverine hydrochloride or prostaglandin E1 are widely recommended in western countries. However, these methods often spoil the erotic mood in the bedroom and the inappropriate use of a VCD may cause pressure necrosis of the numbed penis and self injection has the risk of priapism and infection in those with a spinal cord injury. But a penile prosthesis, once it is successful, is handy, harmless and valuable especially for patients who commonly have urinary troubles.

Our infection rate $(10 \%)$ is as high as that shown in previous reports in which the authors stated their follow up duration. ${ }^{2-4}$ However, we think that the infection rate is unacceptably high. All the patients, who experienced extrusion or required surgical removal because of infection within 3 months, received cephalosporins i.v. where there were no spectra to grampositive organisms. The causative organisms of penile prosthesis infection are mainly gram-positive organisms followed by gramnegative ones. ${ }^{5,10}$ The use of inappropriate antibiotics might be the reason for the high 
Table I Complications leading to loss of penile prosthesis

\begin{tabular}{|c|c|c|c|c|}
\hline Patient & Level of injury & Prosthesis & Interval to loss & Causes \\
\hline 1 & $\mathrm{C} 6$ & SIC & 7 days & Infection $^{\mathrm{a}}$ \\
\hline 2 & $\mathrm{~T} 4$ & SIC & 8 days & Urethral obstruction \\
\hline 3 & T5 & Shirai & 2 weeks & Infection ${ }^{\mathrm{a}}$ \\
\hline 4 & C6 & Shirai & 1 month & Infection ${ }^{a}$ \\
\hline 5 & $\mathrm{~T} 10$ & Shirai & 1 month & Extrusion \\
\hline 6 & $\mathrm{~L} 1$ & Shirai & 1 month & Pain ${ }^{a}$ \\
\hline 7 & $\mathrm{C} 5$ & Shirai & 2 months & Infection $^{\mathrm{a}}$ \\
\hline 8 & $\mathrm{C} 5$ & Shirai & 3 months & Urethral obstruction \\
\hline 9 & $\mathrm{~T} 12$ & SIC & 1 year & Extrusion \\
\hline 10 & L2 & AMS 600 & 1 year & Infection ${ }^{\mathrm{a}}$ \\
\hline 11 & C6 & AMS 600 & 2 years & Infection $^{\mathrm{a}}$ \\
\hline 12 & L5 & Shirai & 2 years & Extrusion $^{\mathrm{a}}$ \\
\hline
\end{tabular}

${ }^{a}$ Removal of the prosthesis

infection rate in the early period. However, Kabalin \& Kessler, ${ }^{5}$ who used the appropriate cephalosporin which is sensitive to gram-positive organisms and aminoglycoside, reported a 3 out of $20(15 \%)$ loss of prosthesis due to infection in the spinal cord injured. Recently, Perkash et al ${ }^{11}$ reported a very low infection rate, as low as $2 \%$. The big difference between their perioperative procedures and ours is the early removal of the indwelling catheter. They remove it within 24 hours after surgery, while we did this on the 7 th day after surgery. Consequently, this earlier removal of the indwelling catheter may reduce the complication rate in the early period. However, four prostheses were lost more than 1 year after the implantation. We could not find any causes which had led to the loss of the prosthesis, such as a prolonged indwelling catheter, or dental or surgical interventions which may disseminate bacteria to the cavernous tissue around the penile prosthesis. These late complications indicate that a strict long term follow up is necessary in patients with a spinal cord injury. We believe that a penile prosthesis is helpful in spinal cord injury patients not only by improving their sexual ability but also by improving their urinary management. However, the patients should be informed of the possibility of a high complication rate. To reduce this high complication rate, the prophylactic use of appropriate antibiotics during the perioperative period and early removal of the indwelling catheter are recommended.

\section{Conclusions}

The satisfactory results of the introduction of a penile prosthesis for the management of the neuropathic bladder and for sexual dysfunction in patients with a spinal cord injury have been presented. Extrusions and infections, however, are still large challenging problems. The infectious complications may have been introduced by the inappropriate use of antibiotics; also, early removal of the indwelling catheter following implantation may be helpful in reducing infectious complications.

\section{Acknowledgement}

The authors are grateful to Dr C E Constantinou for his critical reading of the manuscript.

\section{References}

1 Iwatsubo E, Tanaka M, Takahashi K, Akatsu T (1986) Non-inflatable penile prosthesis for the management of urinary incontinence and sexual disability of patients with spinal cord injury. Paraplegia 24: 307-310.

2 Golji H (1979) Experience with penile prosthesis in spinal cord injury patients. J Urol 121: 288-289. 
3 Van Arsdalen KN, Klein FA, Hackler RH, Brady SM (1981) Penile implants in spinal injury patients for maintaining external appliance. J Urol 126: 331-332.

4 Rossier AB, Fam BA (1984) Indication and results of semirigid penile prostheses in spinal injury patients: long-term follow-up. J Urol 131: 59-62.

5 Kabalin JN, Kessler R (1988) Infectious complications of penile prosthesis surgery. J Urol 139: 953-955.

6 Shirai M, Chiba R (1971) A study on male sexual impotence. Report II. Treatment of organic impotence by implantation of a penile prosthesis (abstract in English). Jpn J Urol 62: 156-161.

7 Smith AD, Sazama R, Lange PH (1980) Penile prosthesis: adjunct to treatment in patients with neurogenic bladder. J Urol 124: 363-364.

8 Nadig PW, Ware JC, Blumoff R (1986) Noninvasive device to produce and maintain an erection-like state. Urology 27: 126-131.

9 Sidi AA, Reddy PK, Chen KK (1988) Patient acceptance of and satisfaction with vasoactive intracavernous pharmacotherapy for impotence. J Urol 140: 293-294.

10 Montague DK (1987) Periprosthetic infections. J Urol 138: 68-69.

11 Perkash I, Kabalin JN, Lennon S, Wolfe V (1992) Use of penile prostheses to maintain external condom catheter drainage in spinal cord injury patients. Paraplegia 30: 327-332. 